\title{
News Photos about Sichuan Earthquake: Effects of Political Ideology and Organizational Goal
}

\section{Clement Y. K. So* and Yuying Dong}

School of Journalism and Communication, The Chinese University of Hong Kong, Shatin, NT, Hong Kong SAR, The People's Republic of China

\begin{abstract}
This paper analyzes how and why some books published by various organizations in different regions of China select photos to record and commemorate the Sichuan earthquake happened on May 12, 2008. A comparison of the photo coverage by the official Chinese news media and the slightly more marketoriented media is done. The ways the mainland Chinese news media and the Hong Kong news media differ in their coverage is also a major objective.

A total of 13 books are included for content analysis and 2,343 photos are analyzed. These books are published by various sources in mainland China and Hong Kong, including the Xinhua News Agency, CCTV, Hong Kong newspaper groups, and a non-profit making organization. We look at the number and types of people shown in the photos and determine the themes of the photos in order to understand what the main messages are. We count the caption words and phrases associated with the photos.

Results show that mainland journalists are more pro-government while Hong Kong journalists are more professional in orientation. Specifically, the Xinhua News Agency photos play up both the central and local officials while the CCTV photos emphasize more on mainland reporters. The mainland books have relatively fewer earthquake scenes, victims' conditions and dead bodies. In contrast, the Hong Kong photos devote more photos to the scenes and ordinary people, as well as their rescue and mourning activities after the earthquake.

The differences in photo coverage are explained by their political affiliations and organizational goals. The clear political and ideological affiliations of Xinhua News Agency and CCTV dictate their roles in reporting the earthquake. The difference in organizational goals between the two mainland media organizations prescribes what they actually did in their coverage of the event. The Hong Kong news practice shows higher level of professionalism while its mainland counterpart is far from satisfactory.
\end{abstract}

\section{Introduction}

On May 12, 2008, an earthquake of 8.0 on the Richter scale hit the Sichuan Province of China, with Wenchuan County as the epicenter. Right after the initial quake, journalists and media organizations from China itself and around the world rushed to this Chinese western city to cover this major disaster. The journalists went beyond normal practices to cover the events, improvising according to circumstances and employing various technologies to meet the continuously high demand for information.

For most Chinese journalists, no matter they are from the Mainland, Hong Kong or Taiwan, covering a disaster of such a mega scale was the first and perhaps once-in-a-life experience. Therefore, immediately after the event, many media outlets published collective memoirs in the forms of articles or books to commemorate the event. They wanted to document the incident and process, express their feelings and emotions, share their experiences with colleagues and the public, and evaluate their professional own performances through these personal accounts. These collective memoirs become a wealth of information for understanding not only the journalists involved in the earthquake coverage but also their respective organizations and locales.

People usually focus on written records to understand and evaluate a particular event as text is the most readily available and rich in quantity and quality. Of course TV news footage is another source of information but it may be difficult to get hold of. Another form of record is news photo which is also in abundance and they usually come together with the news text. In the Sichuan earthquake, not only that a lot of photos were published together with the news stories in newspapers, regular books full of photos and even purely photo books were published and made available to specially commemorate this tragedy.

The objective of this study is to understand how the Chinese journalists portray the earthquake in the news photos. More specifically, we wish to compare the ways photos are used to cover the event by journalists from different regions (mainland China and Hong Kong) as we can expect that they would have different approaches to cover the news event. To go one step further, it would be interesting to discern the subtle differences among the mainland journalists from different news organizations, notably the Xinhua News Agency, CCTV, and other mainland news outlets. Similarly, it would be worthwhile to see if there are internal differences among the Hong Kong journalists. The theoretical impetus of the study is to see the impact of political (and professional) ideology as well as organizational goal on the news photo coverage in the Sichuan earthquake.

\section{The information environment}

The big earthquake in China has generated a lot of attention in the academic research community over the world. A search of

*Corresponding Author: Dr. Clement Y. K. So, School of Journalism and Communication, The Chinese University of Hong Kong, Shatin, NT, Hong Kong SAR, The People's Republic of China; E-mail: clementso@cuhk.edu.hk

Citation: So CYK, Dong Y (2015) News Photos about Sichuan Earthquake: Effects of Political Ideology and Organizational Goal. Int J Journalism Mass Comm 2: 110. doi: http://dx.doi.org/10.15344/2349-2635/2015/110

Copyright: (c) 2015 So et al. This is an open-access article distributed under the terms of the Creative Commons Attribution License, which permits unrestricted use, distribution, and reproduction in any medium, provided the original author and source are credited. 
the Web of Science database using Sichuan earthquake as topic shows a total of 736 documents, most of them from the fields of geochemistry, geophysics, geology and engineering. There are also some related documents from environmental science, remote sensing, water resources, medicine, psychology and psychiatry. Only four of them are from communication.

Two communication studies are about the audience's perception of the news coverage. One is about the relationship between individuals willingness to help disaster victims and their proximal and personal responses to the disaster coverage [1], and the other is about the response to disaster news as mitigated by group identification and social cynicism [2]. Two studies are about government's public relations and media coverage in crisis situations. One discusses the disparity between Chinese media and its international counterparts in news coverage, using the Sichuan earthquake as an example [3]. The other such study deals with the institutionalization of public relations as a government strategic-management function [4].

On the other hand, media coverage of the Sichuan earthquake has triggered abundant reviews and commentaries from China's own academic world. A search through the Chinese Journal Full-Text Database with the keyword "Wenchuan" has located 1,419 articles in all journals in the category of Journalism and Media, in which 103 of them are from the four "core communication journals". A detailed reading of these 103 articles reveals four themes.

The first theme is that the event is a breakthrough in China's media history. Chinese scholars highly praise the media performances in the disaster coverage, acknowledging that among all the media outlets, CCTV pops up as the most outstanding [5-6]. The second theme is about the effects of the media coverage. Chinese scholars [7-8] argue that the successful earthquake coverage has great effect on not only the home audience, but the international world as a whole.

The third theme is a re-consideration of Chinese media's role in disaster reporting. In addition to the responsibilities to provide instant information, Chinese scholars argue that Chinese media should actively and effectively collaborate with the government to unite and encourage the whole nation by telling positive stories, and function as a "helper" of the government instead of a "watchdog" in trying to establish a positive, amiable, caring, reliable, and trustworthy government image [9-10]. The fourth (and minor) theme is about media ethics in disaster reporting. Among the 103 core journal articles, a few of them discuss the ethical issues in disaster reporting, suggesting more considerate and human handling of victim interviewees in the disaster reporting.

Most research concerning natural disasters and media coverage has focused on the analysis of released news text itself [11-12]. Since journalistic reflection is the narratives about the past written by people who make certain news event available to the public, some studies examine not the news articles or programs but reflections made by journalists. The after-event journalistic reflection can be treated as an extension of the continuous media narratives after the occurrence of the earthquake and is, hence, another purposive product of the media other than the news coverage itself. The reflections were published to reconstruct and reinterpret the news events, more importantly inserting the journalists themselves into the story. These journalistic reflections can serve as a direct source for analyzing how journalists purposively promote the stories about themselves.

\section{Media Systems in Mainland China and Hong Kong}

Mainland China is transforming from an authoritarian and regulated society to an authoritarian and neo-liberal society. Despite the great accomplishment of economic reforms and social changes since 1979, it is still under continued political control by the Communist Party. Hong Kong, though reversed from the British colonial ruling, has remained as a free society and the media practitioners mostly subscribe to professionalism [13].

Therefore, in terms of media system, both mainland China and Hong Kong are impacted by market competition. Media in mainland China yields to not only market rules but also authoritative policy. Media in Mainland China have been going through commercialization while having to conform to the continued control [14-15], which results in the co-existence of party organs and media outlets that survive by their appeal to the mass consumers and journalists have to work under intertwined guidance of party ideals of journalism, professionalism imported from the west and the influx of market impetus [16-17].

In China, the Xinhua News Agency is the top state press agency. It reports to the Propaganda Department of the Communist Party Central Committee. Major media outlets at all administrative levels in mainland China are actually state-owned. At the moment of major events, Xinhua News Agency is always the one which sets the tone. No other media will deviate from the "right" track. Therefore, Xinhua News Agency's narrative is very typical the most authoritative one in China.

China Central Television (CCTV) is the top TV station in China's media hierarchy. CCTV is subordinate to the State Administration of Radio, Film, and Television, which also reports to the Propaganda Department of the Communist Party Central Committee. CCTV is always the reference of all the TV stations at lower levels. Moreover, during the earthquake time, most local TV stations in fact solely used CCTV's news signals.

Within China, Xinhua News Agency and CCTV are now experiencing different levels of impact from the market. So comparing the after-event framing of the experience between journalists from the Mainland and Hong Kong may help us understand how Xinhua and CCTV as the most powerful media use narratives about the disaster to establish its authority and legitimation.

It is hoped that by comparing these journalistic reflections from the two Chinese media systems, we can shed some light on the political ideologies and relative degrees of professionalism in the two societies. The examination of the news products by Chinese journalists can enrich the literature by offering a unique theoretical perspective to understand journalistic professionalism in different contexts.

\section{News Photo Studies}

News photos serve various functions. They are used to capture readers' attention, provide information to show what is happening, offer entertainment for people to have a break for serious content, and even establish emotional and psychological links with the readers. They also act as a layout device to break up large gray areas of type, thus making the publication more attractive and readable and helping readers' eyes to move around. Furthermore, they help establish an identity for a news organization by enhancing its modern and streamline look. 
The important role of news photos has been recognized but received less research attention than it deserves. There are several reasons why we should study news photos. The first is based on pure intellectual curiosity as news photos are barely studied and thus little known. Apart from trying to know more about the characteristics of news photos, the usual theoretical interest is to compare the findings about news photos with those from the texts. The second reason for doing so is that photos can be understood from an ideological perspective. Photos can be disguised as objective and neutral. They are supposedly "real" in nature and serve as non-disputable evidence of truth. Pictures are important for readers to better comprehend the stories and form their opinions towards events. News photos lend realism and credibility to the reporting [18]. Furthermore, there are no clearly accepted guidelines to interpret photos. Journalists have more editorial autonomy and control over the choice and description of news photos, and the manipulation, if any, is not easily noticeable by the readers.

A number of studies have tried to decode the meanings connoted by various aspects of a photo. Most of these studies take advantage of the context of U.S. presidential elections and compare the photographic coverage of the two major candidates. An earlier effort by Moriarty and Garramone [19] found that in the 1984 elections some candidates, especially the winning ones, were shown more positively in three news magazines. A later study [20] replicated the above study and found collaborative evidence in the 1988 U.S. presidential elections.

Waldman and Devitt [21] used five measures to analyze newspaper photos of Bill Clinton and Bob Dole in the 1996 presidential campaign. Wanta and Chang [22] examined how 20 newspapers from around the world depicted U.S. President Bill Clinton after the release of the Starr Report. Results show that a newspaper's political leaning was a good predictor as Clinton was shown more positively in conservative papers rather than liberal ones. Among the 10 variables, they found that purpose of photo, camera framing, posture and head position were the more useful ones as they could reach statistically significance when compared across different newspapers.

Photo caption is something worthy of attention. A photo caption usually describes what the photo shows, and gives background on or provides significance of the event [23]. A photo is considered incomplete without a caption as the latter serves to clarify the message of the photo [24]. Captions contain words that can "explain, clarify and add to the image" and they "interpret the photograph, and provide information not found within the image" [25:222]. Photo caption can impart impressions on the readers. There are no generally accepted rules stating how to convey appropriate meanings in the caption. It is the vagueness of caption meaning construction and the takenfor-grantedness of the photos by the readers that make ideological messages in the caption less studied.

\section{Data and Research Method}

After the Sichuan earthquake, many books were published by some media organizations and other publishers in mainland China and Hong Kong to document the incident. Many photos are printed in these books, and some of the books even consist entirely of photos. Compared with photos in the newspapers, books are more easily accessible and photos in these books are more carefully chosen by the editors. The selection process provides more time for the editors and thus the selected photos should be more reflective of their preferences and more revealing about the factors behind choosing these photos.
A total of 13 books are included in this study as sources of data. Three of them (see the Appendix) are published by the Xinhua News Agency and two by CCTV. Another four books are done by mainland publishers but without the official or government-related units. Apart from these nine mainland-published books, four are from several Hong Kong publishers. Two of them are published by different Hong Kong newspaper groups, one by a commercial press, and one by the Hong Kong Journalism Education Foundation (which is a non-profit making organization for the betterment of the Hong Kong journalism industry).

There are more than 2,000 photos in these 13 books about the Sichuan earthquake. We try to extract various types of information from them. First, we look at the number and types of people shown in the photos (whether they are earthquake victims, rescuers, officials, ordinary citizens, reporters, etc.). Second, we determine the themes of the photos in order to understand what the main messages are. Third, we count the caption words and phrases associated with the photos as these words and phrases can provide additional and corroborative information about the nature of these photos.

The coding of the different variables like counting the number of people in the photos and deciding on the number and types of people is rather straight forward. The exception is the decision on the themes of the photos and this requires excising personal judgment by the coders. An intercoder reliability test was performed on this variable and the resulting alpha coefficient [26] is 0.869 , which is within the acceptable range.

In order to understand how news photos from different media organizations and regions depict the earthquake, we divide the 13 books into five groups. The first group has three Xinhua books and the second group includes two CCTV books. The third group consists of four photo books published by different mainland publishers. The fourth group contains three Hong Kong books in which two are published by newspaper organizations in Hong Kong. The fifth group is the single book published by the Hong Kong Journalism Education Foundation (JEF) specifically for professional reflections by Hong Kong journalists.

After the earthquake, anti-disaster rescue news center was instantly set up in order to deal with emergent publicity tasks [10]. Right after May 12, 2008, there was an immediate announcement of the overall guidelines for news reporting at the national level and Sichuan Province. The guidelines set the tone of the disaster reporting as "stick to the idea of uniting and encouraging the people with mainly positive reporting". It is a newly adopted and effective way of control on media through journalists' active understanding and internalization of guidelines provided by the government [10].

Generally speaking, we expect that photos from the mainland/ official sources in China would toe the government line. They will show more government officials of different ranks and the People's Liberation Army, and less on the negative aspects of the event such as mourning scenes and dead bodies. On the other hand, photos from the Hong Kong sources should be less ideological and more professional. They are expected to show more of the victims and the earthquake scenes. The use of photo caption words should also reflect similar patterns regarding photos from different media organizations and places. With diverse political ideologies and organizational goals, we expect different degrees of professional treatment by the different book groups. Xinhua photos are most official, followed closely by 
Citation: So CYK, Dong Y (2015) News Photos about Sichuan Earthquake: Effects of Political Ideology and Organizational Goal. Int J Journalism Mass Comm 2: 110. doi: http://dx.doi.org/10.15344/2349-2635/2015/110

Page 4 of 8

CCTV's. Photos from other mainland sources should be next. The general Hong Kong photos are less ideological in orientation, and those from the JEF book should be closer to the ideal of journalistic professionalism.

\section{Descriptive Findings}

This study has analyzed a total of 2,343 photos as published in the 13 books. Some books have close to 300 photos and the least number of photos in a book still amounts to 84 . In terms of the source of the photos, about two-third of them are from the mainland and one-third from Hong Kong.

A small portion (15.9\%) of the photos has no people and they basically show the scenes of the earthquake areas. Close to onequarter $(24.2 \%)$ of them just showed one person in the photo, and another $14.5 \%$ of them had two persons. Those photos with 3 to 9 people amounted to $25.5 \%$, and those who with 10 or more people totaled $19.9 \%$

Overall speaking, as shown in Table 1, these 2,343 photos as a whole devote the largest share of attention to the earthquake victims (38.2\%). This is quite reasonable and expected. However, it is surprising to know that photos about the People's Liberation Army (PLA) rank second (28.3\%) and those focusing on the mainland reporters come in third (22.5\%). Further down the line we see that other people (including ordinary citizens, medical staff, volunteer helpers and government officials) also get photographed. There were also some mainland central officials (2.9\%) shown prominently in the photos. There were also some mainland local officials (2.6\%) but Hong Kong officials were just photographed twice and Taiwanese officials once.

Table 2 shows the distribution of photo themes in the five book groups. Among the total of 2,343 photos, rescue efforts has the highest share $(27.8 \%)$ and it is congruent with our expectation. The proportions of photos on earthquake scenes (14.7\%) and on victims' conditions (14.3\%) ranked third and fourth respectively. They also look very reasonable. One strange category which ranks second is "reporters at work" and it has a share of $19.2 \%$. A related category called "reporters' memorial shots" has $6.1 \%$ (which are like tourist snapshots). Other themes found in the photos include mourning activities, death scenes, central officials' activities, and citizens' activities.

Among the top 50 caption words and phrases in the photos, "earthquake" is naturally the most frequently used word (Table 3 ).

\begin{tabular}{|l|l|l|l|l|l|l|l|}
\hline Type of People in Photo & $\begin{array}{l}\text { Xinhua } \\
(\mathrm{N}=352)\end{array}$ & $\begin{array}{l}\text { CCTV } \\
(\mathrm{N}=397)\end{array}$ & $\begin{array}{l}\text { Other Mainland } \\
(\mathrm{N}=808)\end{array}$ & $\begin{array}{l}\text { Hong Kong } \\
(\mathrm{N}=569)\end{array}$ & JEF (N=217) & Total (N=2,343) & Cramer's V \\
\hline Victims & 39.5 & 23.2 & 42.5 & 40.9 & 41.0 & 38.2 & $.142^{* * *}$ \\
\hline People's Liberation Army & 30.7 & 18.1 & 34.3 & 26.7 & 25.3 & 28.3 & $.126^{* * *}$ \\
\hline Mainland reporters & 34.9 & 62.5 & 18.3 & 0.9 & 1.8 & 22.5 & $.509^{* * *}$ \\
\hline 10 or more people shown & 25.0 & 10.3 & 19.9 & 23.2 & 21.7 & 20.0 & $.133^{* * *}$ \\
\hline No people shown & 8.0 & 11.8 & 19.6 & 19.5 & 13.4 & 15.9 & $.133^{* * *}$ \\
\hline Citizens & 6.5 & 1.3 & 3.6 & 17.8 & 12.0 & 7.9 & $.233^{* * *}$ \\
\hline Dead bodies & 1.7 & 0.0 & 6.9 & 8.1 & 6.0 & 5.2 & $.139^{* * *}$ \\
\hline Medical staff & 8.0 & 3.0 & 5.2 & 3.2 & 2.8 & 4.5 & $.084^{* *}$ \\
\hline Helpers & 3.1 & 3.5 & 4.3 & 5.8 & 4.1 & 4.4 & .045 (ns) \\
\hline Central officials & 15.3 & 0.0 & 0.2 & 1.9 & 0.0 & 2.9 & $.318^{* * *}$ \\
\hline Local officials & 10.5 & 3.5 & 0.9 & 0.5 & 0.5 & 2.6 & $.216^{* * *}$ \\
\hline Hong Kong reporters & 0.0 & 0.0 & 0.1 & 0.4 & 23.0 & 2.3 & $.447^{* * *}$ \\
\hline
\end{tabular}

Table 1: Coverage of Various People in Five Book Groups (\%).

\begin{tabular}{|c|c|c|c|c|c|c|}
\hline Photo Theme & $\begin{array}{l}\text { Xinhua } \\
(\mathrm{N}=352)\end{array}$ & $\begin{array}{l}\text { CCTV } \\
(\mathrm{N}=397)\end{array}$ & $\begin{array}{l}\text { Other Mainland } \\
(\mathrm{N}=808)\end{array}$ & $\begin{array}{l}\text { Hong Kong } \\
(\mathrm{N}=569)\end{array}$ & $\mathrm{JEF}(\mathrm{N}=217)$ & $\begin{array}{l}\text { Total } \\
(\mathrm{N}=2,343)\end{array}$ \\
\hline Rescue efforts & 27.8 & 11.6 & 34.0 & 32.9 & 21.2 & 27.8 \\
\hline Reporters at work & 23.6 & 53.9 & 14.0 & 0.4 & 17.1 & 19.2 \\
\hline Earthquake scenes & 8.0 & 6.8 & 18.6 & 18.8 & 15.2 & 14.7 \\
\hline Victims' conditions & 8.0 & 8.3 & 16.1 & 19.0 & 16.1 & 14.3 \\
\hline Mourning activities & 2.3 & 1.3 & 4.2 & 18.5 & 8.8 & 7.3 \\
\hline Reporters' memorial shots & 9.7 & 15.9 & 4.0 & 0.0 & 6.0 & 6.1 \\
\hline Death scenes & 1.1 & 0.0 & 6.7 & 5.8 & 4.1 & 4.3 \\
\hline Central officials' activities & 15.6 & 0.0 & 0.2 & 1.9 & 0.0 & 2.9 \\
\hline Citizens' activities & 2.8 & 1.5 & 2.2 & 1.2 & 6.5 & 2.3 \\
\hline Others themes & 1.1 & 0.8 & 0.0 & 1.6 & 5.1 & 1.2 \\
\hline Total & 100.0 & 100.1 & 100.0 & 100.1 & 100.1 & 100.1 \\
\hline
\end{tabular}

Table 2: Comparison of Photo Themes in Five Book Groups (\%).

Cramer's V $=.341^{* * *}$ 
Citation: So CYK, Dong Y (2015) News Photos about Sichuan Earthquake: Effects of Political Ideology and Organizational Goal. Int J Journalism Mass Comm 2: 110. doi: http://dx.doi.org/10.15344/2349-2635/2015/110

Page 5 of 8

\begin{tabular}{|c|c|c|c|c|c|c|c|}
\hline Word & Category & $\begin{array}{l}\text { Xinhua } \\
(\mathrm{N}=2,771)\end{array}$ & $\operatorname{CCTV}(\mathrm{N}=848)$ & $\begin{array}{l}\text { Other Mainland } \\
(\mathrm{N}=1,639)\end{array}$ & $\begin{array}{l}\text { Hong Kong } \\
\text { Others }(\mathrm{N}=1,548)\end{array}$ & $\begin{array}{l}\text { Hong Kong } \\
\text { JEF }(\mathrm{N}=1,142)\end{array}$ & $\begin{array}{l}\text { Total } \\
(\mathrm{N}=7,948)\end{array}$ \\
\hline Earthquake & disaster & $100(1)$ & $9(10)$ & $2(166)$ & $48(1)$ & $59(1)$ & $309(1)$ \\
\hline Sichuan & place & & $5(35)$ & $46(3)$ & $35(3)$ & $29(4)$ & $213(2)$ \\
\hline Wenchuan & place & $89(2)$ & $10(6)$ & $42(4)$ & $15(16)$ & $20(10)$ & $176(3)$ \\
\hline Ruin & scene & $66(3)$ & $3(61)$ & $51(2)$ & $42(2)$ & $12(18)$ & $174(4)$ \\
\hline Disaster area & scene & $46(7)$ & $13(4)$ & $52(1)$ & $26(6)$ & $29(4)$ & $166(5)$ \\
\hline Beichuan & place & $57(4)$ & $9(10)$ & $37(5)$ & $20(10)$ & $18(12)$ & $141(6)$ \\
\hline Coverage & action & $54(5)$ & $26(2)$ & $18(13)$ & $3(113)$ & $26(6)$ & $127(7)$ \\
\hline Student & people & $37(9)$ & $3(61)$ & $24(8)$ & $32(4)$ & $22(9)$ & $118(8)$ \\
\hline Dujiangyan & place & $29(13)$ & $7(21)$ & $26(6)$ & $21(9)$ & $32(2)$ & $115(9)$ \\
\hline Yingxiu & place & $45(8)$ & $2(109)$ & $21(11)$ & $11(21)$ & $32(2)$ & $111(10)$ \\
\hline Reporter & people & $14(45)$ & $45(1)$ & $13(21)$ & $4(82)$ & $26(6)$ & $102(11)$ \\
\hline Victim & people & $22(26)$ & $4(45)$ & $13(21)$ & $26(7)$ & $24(7)$ & $89(12)$ \\
\hline Rescuer & people & $28(13)$ & & $17(15)$ & $30(5)$ & $12(18)$ & $87(13)$ \\
\hline Child & people & $25(20)$ & $5(35)$ & $22(9)$ & $14(18)$ & $17(14)$ & $83(14)$ \\
\hline Rescue & action & $27(15)$ & $5(35)$ & $25(7)$ & $11(21)$ & $2(126)$ & $70(15)$ \\
\hline Found dead & disaster & $26(18)$ & $1(245)$ & $22(9)$ & $9(29)$ & $5(38)$ & $63(16)$ \\
\hline Anti-quake \& rescue & action & $49(6)$ & $7(21)$ & $3(113)$ & $3(113)$ & & $62(17)$ \\
\hline Chengdu & place & $17(36)$ & $7(21)$ & $13(21)$ & $6(46)$ & $17(14)$ & $60(18)$ \\
\hline Mass public & people & $43(8)$ & & $9(34)$ & $5(61)$ & $1(278)$ & $58(19)$ \\
\hline Hanwang & place & $14(45)$ & & $19(12)$ & $15(16)$ & $7(27)$ & $55(20)$ \\
\hline Helicopter & scene & $26(18)$ & $9(10)$ & $9(34)$ & $3(113)$ & $5(38)$ & $52(21)$ \\
\hline May 14 & date & $26(18)$ & $5(35)$ & $17(15)$ & & $4(56)$ & $52(21)$ \\
\hline Fallen & disaster & $17(36)$ & & $9(34)$ & $10(25)$ & $15(16)$ & $51(23)$ \\
\hline Liberate & action & $17(36)$ & & $8(40)$ & $17(13)$ & $8(24)$ & $50(24)$ \\
\hline Broken tile & scene & $7(80)$ & & $3(113)$ & $20(10)$ & $18(12)$ & $48(25)$ \\
\hline May 13 & date & $29(12)$ & $3(61)$ & $13(21)$ & & $2(126)$ & $47(26)$ \\
\hline Soldier & people & $35(10)$ & & $6(53)$ & $4(82)$ & $2(126)$ & $47(26)$ \\
\hline Mianzhu & place & & $1(245)$ & $22(9)$ & $16(15)$ & $7(27)$ & $46(28)$ \\
\hline May 16 & date & $27(15)$ & $8(15)$ & $8(40)$ & & $3(83)$ & $46(28)$ \\
\hline Victimized & disaster & $35(10)$ & & $6(53)$ & $3(113)$ & & $44(30)$ \\
\hline Salvage & action & $23(24)$ & & $9(34)$ & $6(46)$ & $6(31)$ & $44(30)$ \\
\hline PLA & people & $19(31)$ & & $5(68)$ & $8(34)$ & $11(20)$ & $43(32)$ \\
\hline Mianyang & place & $23(24)$ & $4(45)$ & $6(53)$ & $6(46)$ & $3(83)$ & $42(34)$ \\
\hline Hour & others & $6(84)$ & $4(45)$ & $16(18)$ & $15(16)$ & $1(278)$ & $42(34)$ \\
\hline May 15 & date & $20(28)$ & $7(21)$ & $11(27)$ & & $4(56)$ & $42(34)$ \\
\hline Shifang & place & $15(41)$ & $1(245)$ & $14(20)$ & $9(29)$ & $3(83)$ & $42(34)$ \\
\hline Cadaver & scene & $11(59)$ & & $17(15)$ & $8(34)$ & $4(56)$ & $40(37)$ \\
\hline Heavy casualty area & scene & $20(28)$ & & $5(68)$ & $9(29)$ & $4(56)$ & $38(39)$ \\
\hline Disaster situation & scene & $24(21)$ & & $1(348)$ & $4(82)$ & $9(21)$ & $38(39)$ \\
\hline Silent mourning & action & $6(84)$ & $2(109)$ & $9(34)$ & $17(13)$ & $4(56)$ & $38(39)$ \\
\hline Life & others & $3(170)$ & $2(109)$ & $4(86)$ & $26(7)$ & $2(126)$ & $37(41)$ \\
\hline School & scene & $11(59)$ & $2(109)$ & $8(40)$ & $9(29)$ & $6(31)$ & $36(42)$ \\
\hline Armed police & people & $20(24)$ & & $8(40)$ & $5(61)$ & $3(83)$ & $36(42)$ \\
\hline May17 & date & $14(45)$ & $3(61)$ & $17(15)$ & & $1(278)$ & $35(44)$ \\
\hline Hurt & disaster & $16(39)$ & & $10(29)$ & $6(46)$ & $2(126)$ & $34(46)$ \\
\hline
\end{tabular}


Citation: So CYK, Dong Y (2015) News Photos about Sichuan Earthquake: Effects of Political Ideology and Organizational Goal. Int J Journalism Mass Comm 2: 110. doi: http://dx.doi.org/10.15344/2349-2635/2015/110

Page 6 of 8

\begin{tabular}{|c|c|c|c|c|c|c|c|}
\hline Canvas & scene & $13(50)$ & $8(15)$ & $4(86)$ & $5(61)$ & $4(56)$ & $34(46)$ \\
\hline Reporting & action & $7(80)$ & $24(3)$ & $1(348)$ & & $2(126)$ & $34(46)$ \\
\hline Covered & disaster & $12(54)$ & $1(245)$ & $8(40)$ & $8(34)$ & $4(56)$ & $33(48)$ \\
\hline Corpse & scene & & & $1(348)$ & $12(19)$ & $19(12)$ & $32(49)$ \\
\hline Qingchuan & place & $15(41)$ & 2 (109) & $9(34)$ & $5(61)$ & $1(278)$ & $32(49)$ \\
\hline \multicolumn{8}{|c|}{$\begin{array}{l}\text { Table 3: Top } 50 \text { Caption Words and Phrases in Five Book Groups }{ }^{*} \\
\text { * The number outside bracket is the frequency; number inside bracket is the rank. } \\
\text { For the rest of the words in the five book groups: } \\
\text { Xinhua: } 24 \text { (22): Hu Jintao; } 19 \text { (31): collapse, May12, May19; } 18 \text { (34): hospital; } 16 \text { (39): injured, Wen Jiabao; } 15 \text { (41): army; } 14 \text { (45): CCP politburo executive member, Xinhua Ne } \\
\quad \text { Agency, Juyuan Middle School } \\
\text { CCTV: } 10 \text { (6): program, live scene; } 9 \text { (10): live broadcast, news channel; } 8 \text { (15): broadcast, shooting, Bai Yansong; } 7 \text { (21): CCTV, united broadcast, news center, Ji Huiyan } \\
\text { Other mainland: } 12 \text { (25): survivor; } 10 \text { (29): after quake, soldier; } 9 \text { (34): save; } 8 \text { (40): rescue, injured, Tan Qianqiu; } 7 \text { (45): Beichuan Middle School, rescue, volunteers } \\
\text { Hong Kong others: } 17 \text { (13): relative; } 11 \text { (21): compatriot, military person; } 10 \text { (25): citizens tragedy; } 9 \text { (29): rescue team; } 8 \text { (34): hope, rescued; } 7 \text { (38): big rock, covered, save } \\
\text { Hong Kong JEF: } 14 \text { (17): parent; } 9 \text { (21): Yingxiu Primary School; } 8 \text { (24): disaster scene, Hong Kong; } 7 \text { (27): mother, trapped; } 6 \text { (31): wounded, citizen; } 5 \text { (38): Xiange Middle } \\
\quad \text { School, child, remembrance, on foot }\end{array}$} \\
\hline
\end{tabular}

The next two words refer to the location of the disaster, namely "Sichuan" and "Wenchuan". "Ruin" and "disaster area" rank fourth and fifth respectively. Apart from the other words about location ("Beichuan", "Dujiangyan" and "Yingxiu"), "coverage" and "student" fill the last two spots on the top 10 word list. Some other frequently used words include: "reporter", "victim", "rescuer", "child", and "found dead".

If we group these 50 caption words and phrases into different categories, 11 of them are about places such as "Sichuan", "Wenchuan", "Dujiangyan", and "Yingxiu". A similar proportion $(\mathrm{N}=10)$ is about the various scenes, including "ruin", "disaster area", "broken tile", "cadaver", "school", etc. Some groups of people ( $\mathrm{N}=9)$ are mentioned frequently such as "student", "reporter", "victim", "rescuer", "child", "mass public", "soldier", etc. Certain actions ( $\mathrm{N}=7)$ are highlighted, which include "press coverage", "rescue", and "silent mourning". Several words and phrases $(\mathrm{N}=6)$ are directly related to disaster $(\mathrm{N}=6)$ : "earthquake", "found dead", "fallen", and "hurt". There are also mentioning of the exact dates $(\mathrm{N}=5)$ from May 13 to 17.

\section{Results from the Comparative Analysis}

The coverage of people in the photos of the different groups of books does show some interesting differences (Table 1). For the two Xinhua books, they are keen on showing the central officials (15.3\%) and local officials (10.5\%). For example, Party Chief Hu Jintao and Premier Wen Jiabao are shown 18 and 14 times respectively. The total for all central government officials is $\mathbf{5 4}$ and for all local officials is 37. As a contrast, for the other 11 books combined, $\mathrm{Hu}$ and Wen are shown only 5 and 9 times respectively. The figures for central and local officials are only 14 and 25 respectively. It is clear that the Xinhua books not only serve as official mouthpiece but directly show the party officials and their involvement in the post earthquake rescue work. Apart from showcasing the officials, the Xinhua books also highlight the mainland reporters in the photos in which many of them are Xinhua reporters and personnel. But these two books show comparatively less interest in covering the generic earthquake scenes (without people in them) and the dead bodies.

The three CCTV books are distinctly different in their photo contents. A whopping majority (62.5\%) of photos involve the mainland (CCTV) reporters at the expense of other people, including the victims (only 23.3\%) and the PLA (18.1\%) as distant second and third. They also show much fewer photos on the ordinary citizens and no single photo on the dead bodies. This should be a deliberate editorial choice not to do so.
For the other three types of books, the "other mainland" type shows somewhat more on the PLA. The "Hong Kong" type devotes more photos to the ordinary citizens in their actions and feelings. For the Hong Kong JEF book, it also has more on the citizens and the Hong Kong reporters, but less on the mainland reporters. This is perfectly understandable as this book is a conscious reflection effort on how the Hong Kong journalists perform in the earthquake coverage.

We find that photos about the reporters are in fact mainly contributed by the CCTV and Xinhua books. As shown in Table 2, the two CCTV books have more than half of their photos $(53.9 \%)$ devoted to showing their own reporters at work, and another $15.9 \%$ of the photos are of "memorial" type of shots by the reporters. In other words, close to $70 \%$ of these CCTV shots are about their own reporters, constituting the image of self documentation and even self promotion. On the contrary, the CCTV and Xinhua books again have very few photo coverage on the earthquake scenes, victims' conditions, mourning activities, and particularly the death scenes. The official line is clearly not to show too much of the dreadful scenes and dead bodies, as the main focus of earthquake reporting should be more positive on how the government and the media can deal with the disaster. This is exemplified by the relatively high proportion of central officials' activities shown by the Xinhua books.

For the other three book groups, their photo themes are quite similar to the overall distribution of themes. There are a few deviations though. The other mainland books have slightly more photos on the rescue efforts. The Hong Kong books (not including the JEF book) print more mourning activity photos and the victims' conditions. The JEF book devotes slight more to citizens' activities but less on rescue efforts, and none on the central officials' activities.

Like the photo content, photo captions from the Xinhua books focus more on the government officials. "Hu Jintao" is mentioned 19 times and "Wen Jiabao" 15 times. Other politburo standing committee members are mentioned 14 times. "Soldier" (35), "armed police" (20), "PLA" (19), "army" (14), and "Xinhua" itself (14) also appear frequently in the captions. It is interesting to note that the Xinhua captions never mention the location "Sichuan" and use "Wenchuan" instead.

CCTV books' photo caption words and phrases have more to do with news coverage than anything else. The word "reporter" is ranked first, "coverage" second, and "reporting" third. Other TV reporting related words such as "program", "live scene", "live broadcast", "helicopter", 
"news channel", "broadcast", "shooting" and "united broadcast" are high on the list. "CCTV" itself is also mentioned quite frequently. Compared to other book captions, CCTV's are low on people ("PLA", "mass", "student", "victim"), scenes ("casualty area"), situations ("dead body", "casualty", "rescue", "fallen"), places ("Yingxiu", "Mianju”). This is because TV related coverage has taken up a large number of the caption words already and there is not much room for describing other aspects of the earthquake.

For the caption words in the other mainland books, we see there are more on the scenes (such as "rescue", "dead", "child" and "dead body") but less on the word "earthquake". Among the Hong Kong books, the caption words pay more attention to "compatriot", "relative", "life", "school", "mourning" and "rescue", and less on "reporter" and "reporting". The JEF book has higher frequencies on "Hong Kong", "parent" and "mother", but less on "mass public".

\section{Conclusion and Discussion}

Results from the above sections show that mainland journalists' photo treatment of the Sichuan earthquake is more pro-government as shown in their coverage of government officials and the PLA. For the Hong Kong journalists, they seem more professional in work orientation by caring more about the victims and focusing less on officials or reporters. The differences in photo coverage by these books can be explained by their ideological affiliations and organizational goals.

Xinhua News Agency as a government organ had to absorb the government's guideline in its work and ideology. Xinhua was fully government-funded, and was born to have officially authoritative status. It provides information to the government and other news media, but it never has to worry about market demands. Without the pressure of readership and profit, Xinhua's narratives endeavor only to demonstrate its inherent authoritative position and to satisfy the government officials. A Xinhua journalist reveals that it was crucial to document what Premier Wen did during his stay in Sichuan and he understands "to document" is to closely follow Wen and try to catch the most touching moments [27]. For the three Xinhua books, they have dual purposes of self promotion as well as documentation and memorial function.

In contrast, the CCTV photos emphasized more on the mainland reporters, especially those "tourist snapshots" showing the reporters in front of earthquake scenes. CCTV has given much more salience to individual reporters by devoting $62.5 \%$ pictures in the book to the stories about the journalists themselves rather than the disaster story. In contrast, the Hong Kong books on the average have used less than $10 \%$ of their pictures to show the journalists. CCTV is selling the stories about its own. The mainland books have relatively fewer earthquake scenes, victims' conditions and dead bodies. It is clear that the publication purpose of the CCTV books is primarily for promotion of self-image.

Unlike Xinhua, CCTV is not so lucky to have inborn authority status. It has been thrown into the market to survive with a leash on its neck. So CCTV has tried its best to legitimate its status as an authoritative interpreter of the news occurrences. At the same time CCTV must demonstrate its excellence and legitimize their authority to win over the public. As a self-funded media outlet, CCTV has to play the cards of professionalism and emotions to establish a reliable, trust-worthy and caring image in order to appeal to its audience [28]. The pressure to appeal to both the government and the audience has forced CCTV to self advertise its strengths and characteristics.

In contrast to its Mainland counterparts, Hong Kong media have received no direct government interference. They are basically guided by professionalism borrowed from the western world, and at the same time driven by fierce market competition [29-30]. Hong Kong photos devote more coverage to the earthquake scenes and ordinary people, as well as their rescue and mourning activities after the earthquake. The basic objective of the Hong Kong books is to document the earthquake tragedy and in memory of the victims.

There is not much difference between the three Hong Kong books and the JEF book, as their original sources are mainly from the Hong Kong journalists. One minute difference is that the JEF book has a special purpose to reflect on professional performance of the Hong Kong reporters in this event. Apart from documenting the rescues, earthquake scenes and victims' conditions, it also looks at how the reporters were at work. This book even openly talks about government control over the media in the mainland [31].

The clear political and ideological affiliations of Xinhua News Agency and CCTV dictate their roles in reporting the earthquake. The difference in organizational goals between the two mainland media organizations prescribes what they actually did in their coverage of the event. The photo patterns between their books and other less official publications in the mainland are clearly different as shown by the results of this study. Their contrast with the Hong Kong photos is very stark. If the Hong Kong news practice is used as a comparative yardstick to gauge the level of professionalism shown by its mainland counterparts, the performance of major official Chinese news organizations is still far from satisfactory.

\section{Competing Interests}

The authors have no competing interests with the work presented in this manuscript.

\section{References}

1. Seo M, et al. (2012) Willingness to help following the Sichuan earthquake: Modeling the effects of media involvement, stress, trust, and relational resources. Communication Research 39: 3-25.

2. Chen SX, Guan Y, Hui CM (2012) Responding to news about a natura disaster: The interplay of group identification and social cynicism in perceived prototypicality. International Journal of Intercultural Relations 36 : 586-597.

3. Sun W (2010) Mission impossible? Soft power, communication capacity, and the globalization of Chinese media. International Journal of Communication 4: 54-72.

4. Chen N (2009) Institutionalizing public relations: A case study of Chinese government crisis communication on the 2008 Sichuan earthquake. Public Relations Review 35: 187-198.

5. Han B (2008) To Record History and to Create History. In: Liang X (Ed) Convulsion: Media Review, China Democracy and Law Press, Beijing, pp 388-393.

6. Yu W (2009) The successful photojournalistic practice in disaster reporting. The Press 9: 89-91.

7. Chen $P(2010)$ The periodical functions of media in disaster reporting. News Window 4: 34-35

8. Liu X, Liu X, Lu X (2009) Embody the humanistic concern in disaster reporting. Press Circles 6: 101-102, 90.

9. Jiang $Y(2009)$ Media's guiding of the public opinion in unexpected public crisis. News circles $4: 6-8$ 
Citation: So CYK, Dong Y (2015) News Photos about Sichuan Earthquake: Effects of Political Ideology and Organizational Goal. Int J Journalism Mass Comm 2: 110. doi: http://dx.doi.org/10.15344/2349-2635/2015/110

10. Wang $\mathrm{H}$ (2009) From a big media country to a strong media country. Journalism Fans 12: 11-12.

11. Kreps GA (1980) Research Needs and Policy Issues on Mass Media Disaster Reporting. In: Committee on Disasters and the Mass Media (Ed) Disasters and the Mass Media, National Academy of Sciences, Washington DC, pp. 35-74.

12. Wenger DE, Quarantelli EL (1989) Local Mass Media Operations, Problems and Products in Disasters. Newark: Disaster Research Center, University of Delaware, USA.

13. So CYK, Chan JM (2007) Professionalism, politics and market force: Survey studies of Hong Kong journalists 1996-2006. Asian Journal of Communication 17: 148-158.

14. Chan JM (1993) Commercialization without Independence: Media Development in China. In: Cheng J, Brosseau M (Eds) China Review 1993 Chinese University Press, Hong Kong, pp. 1-19.

15. Lee CC (1994) Ambiguities and Contradiction: Issues in China's Changing Political Communication. In: Lee CC (Ed) China's Media, Media's China, Westview, Boulder, pp. 3-20.

16. Pan Z, Chan JM (2003) Shifting journalistic paradigms: How China's journalists assess "media exemplars". Communication Research 30: 649682.

17. Zhao Y (1998) Media Market, and Democracy in China: Between the Party Line and the Bottom Line. Urbana \& Chicago: University of Illinois Press, USA.

18. Graber DA (1988) Processing the News: How People Tame the Information Tide. (2 edition), White Plains, NY: Longman, USA.

19. Moriarty SE, Garramone GM (1986) A study of newsmagazine photographs of the 1984 presidential campaign. Journalism Quarterly 63: 728-734.

20. Moriarty SE, Popovich MN (1991) Newsmagazine visuals and the 1988 presidential election. Journalism Quarterly 68: 371-380.

21. Waldman P, Devitt J (1998) Newspaper photographs and the 1996 presidential election: The question of bias. Journalism Quarterly 75: 302-

22. Wanta W, Chang KK (2000) Visual depictions of President Clinton in the international press after the release of the Starr Report. Paper presented at the ICA annual convention, Acapulco, Mexico, June.

23. Wanta W, Ryan W, Lee T, Chang K (1999) Looking presidential: A comparison of newspaper photographs of candidates in the U.S. and Taiwan. Paper presented at the annual convention of the International Communication Association, San Francisco.

24. Hoy FP (1993) Photojournalism: The Visual Approach. (2nd edition), Englewood Cliffs, NJ: Prentice Hall, USA.

25. Lewis G (1995) Photojournalism: Content and Technique. (2nd edition), Madison, WI: Brown \& Benchmark, USA.

26. Krippendorff K (2013) Content Analysis: An Introduction to its Methodology (3rd edition), Thousand Oaks, CA: Sage, USA.

27. Li B (2008) Four Times Following Premier Wen to the Disaster Area. In: Xinhua Editor-in-chief Office (Ed) Xinhua News Agency Journalists' Personal Experiences in Wenchuan Earthquake, Xinhua Press, Beijing pp. 16-24.

28. Dong KY, So CYK (2011) Chinese media's eulogy of the Wenchuan earthquake coverage: A comparative analysis. Paper presented at the 2011 Conference of the Association for Education in Journalism and Mass Communication, St. Louis, August 10-13.

29. Chan JM, Lee CC (1991) Mass Media and Political Transition: The Hong Kong Press in China's Orbit. New York: Guilford Press, USA.

30. So CYK, Chan JM, Lee CC (2000) Hong Kong SAR (China). In: Guarantee $\mathrm{SA}$ (Ed) Handbook of the Media in Asia, Sage, New Delhi, pp. 527-551.

31. Tang CF (2008) Can Bear Adding Salt to the Wound. In: So CYK, Chan ESC, Owen EOM, Chan PK (Eds) Sichuan Earthquake: Reflections of Hong Kong Journalist, Hong Kong Journalism Education Foundation, Hong Kong, pp. 96-99. 